\title{
Desenvolvimento juvenil de Hepatus pudibundus (Herbst) (Crustacea, Decapoda, Calappidae), em laboratório
}

\author{
Nilton José Hebling ${ }^{1} \&$ Paulo Juarez Rieger ${ }^{2}$
}

\author{
${ }^{1}$ Departamento de Zoologia, Instituto de Biociências, Universidade Estadual Paulista. Caixa Postal 199, 13506-900 Rio \\ Claro, São Paulo, Brasil. \\ 2 Laboratório Zoologia Crustacea Decapoda, Departamento de Ciências Morfo-biológicas, Universidade Federal do Rio \\ Grande. Avenida Itália, Km 08, Caixa Postal 474, 96201-900 Rio Grande, Rio Grande do Sul, Brasil. \\ E-mail:dmbpjr@super.furg.br
}

ABSTRACT. Juvenile development of Hepatus pudibundus (Herbst) (Crustacea, Decapoda, Calappidae) in laboratory. The Hepatus pudibundus (Herbst, 1785) juvenile development was studied in laboratory, under the morphological and systematical stand points. The eight early juvenile stages were obtained from larvae hatched from eggs of two ovigerous females, collected at the northern coast of the State of São Paulo, Brazil. The experiments were carried out in a climatically controlled room at $25 \pm$ $1{ }^{\circ} \mathrm{C}$, and steady saltness of $34^{\circ} \%$ oo The youngs were maintened individually and food consisted of Artemia sp. nauplii and fragments of fish muscle.The first juvenile stage were particulary drawn and described. For the remaining juvenile stages the most representative frameworks were picked out, which allowed the characterization of the first eight stages. According to juvenile morphology studies, it was noted that secondary sexual characters differentation begins from the third stage.

KEY WORDS. Brachyura, juvenile stages, morphology.

Em decorrência de sua grande abundância em águas rasas do litoral norte do Estado de São Paulo, Hepatus pudibundus (HERBsT, 1785) tem sido utilizado como material de estudo em várias pesquisas, que contribuíram não somente para um melhor conhecimento da espécie mas também para a avaliação de alguns parâmetros biológicos e ambientais de maior amplitude, implicados em outros grupos de crustáceos. Assim, Mantelatto \& Fransozo $(1992,1994)$ analisando os dados biométricos das populações da região de Ubatuba, São Paulo, durante o ciclo anual, determinaram o tamanho em que a espécie atinge a muda da puberdade e o crescimento relativo dos machos e fêmeas. Rieger \& Hebling (1993) estudaram o desenvolvimento larval de H. pudibundus, com ênfase na determinação e avaliação do número de estágios larvais, suas descrições morfológicas e implicações filogenéticas. Reigada et al. (1994) analisaram o tamanho dos quelípodos, em relação à dieta e à dinâmica reprodutiva. Reigada \& NEgreiros-Fransozo (1995) avaliaram a fecundidade, relacionando-a com a taxa de sobrevivência larval. Mantelatto et al. (1995a) determinaram a estrutura populacional, com interpretação do "sex-ratio" no ciclo anual, os períodos de maior atividade reprodutiva e o tipo de reprodução da espécie. Mantelatto et al. (1995b) Caracterizaram a distribuição espacial de H. pudibundus, na enseada da fortaleza, em função de alguns fatores físicos e químicos registrados nas radiais de coleta. Mantelatto \& Petracco (1997) analisaram a dieta natural da espécie e Reigada \& Negreiros-Fransozo (1999) determinaram o tamanho de maturidade sexual fisiológica, correlacionando-a com a maturidade morfológica e o ciclo de mudas.

O objetivo deste trabalho, inédito para a família Calappidae, é o estudo dos oito primeiros estágios juvenis de $H$. pudibundus, obtidos e mantidos em laboratório, após os traba- lhos prévios sobre desenvolvimento larval da espécie. A partir das descrições detalhadas do primeiro estágio juvenil, são apresentados os principais caracteres que permitem a identificação dos estágios subsequentes, os intervalos de tempo e o crescimento entre as ecdises sucessivas, a diferenciação dos caracteres sexuais secundários e uma análise comparativa com outras famílias de Brachyura, estudadas sob este aspecto.

\section{MATERIAL E MÉTODOS}

Hepatus pudibundus (Fig. 1) vive preferencialmente em fundos lamosos, areia e conchas, desde águas rasas até $160 \mathrm{~m}$. Apresenta ampla distribuição geográfica no Atlântico ocidental - Georgia, Golfo do Máxico, Antilhas, Venezuela, Guianas e Brasil (do Amapá ao Rio Grande do Sul) e no Atlântico Oriental - da Guiné a África do Sul (Melo 1996).

Os exemplares utilizados neste trabalho foram coletados com o auxílio de uma rede do tipo "otter trawl", em arrastos efetuados entre 14 e $18 \mathrm{~m}$ de profundidade, entre a ilha Anchieta e o continente $\left(23^{\circ} 32^{\prime} 05^{\prime \prime}\right.$ a $\left.23^{\circ} 33^{\prime} 20^{\prime \prime} \mathrm{S}, 45^{\circ} 05^{\prime} 30^{\prime \prime} \mathrm{W}\right)$, no litoral norte do Estado de São Paulo.

As fêmeas ovígeras foram colocadas em caixas de isopor, transportadas para o laboratório e mantidas isoladas em aquários com aproximadamente 10 litros de água do mar, com salinidade $34 \%$, continuamente aerada. Os aquários foram colocados em uma câmara climática com temperatura de $25 \pm$ $1^{\circ} \mathrm{C}$, sob fotoperiodismo natural.

Após a eclosão, as larvas (Zoeas I) destinadas aos estudos do desenvolvimento pós-embrionário foram atraídas por um foco de luz, removidas do aquário com um conta-gotas e transferidas, isoladamente, para placas de Petri de $20 \mathrm{ml}$, pro- 


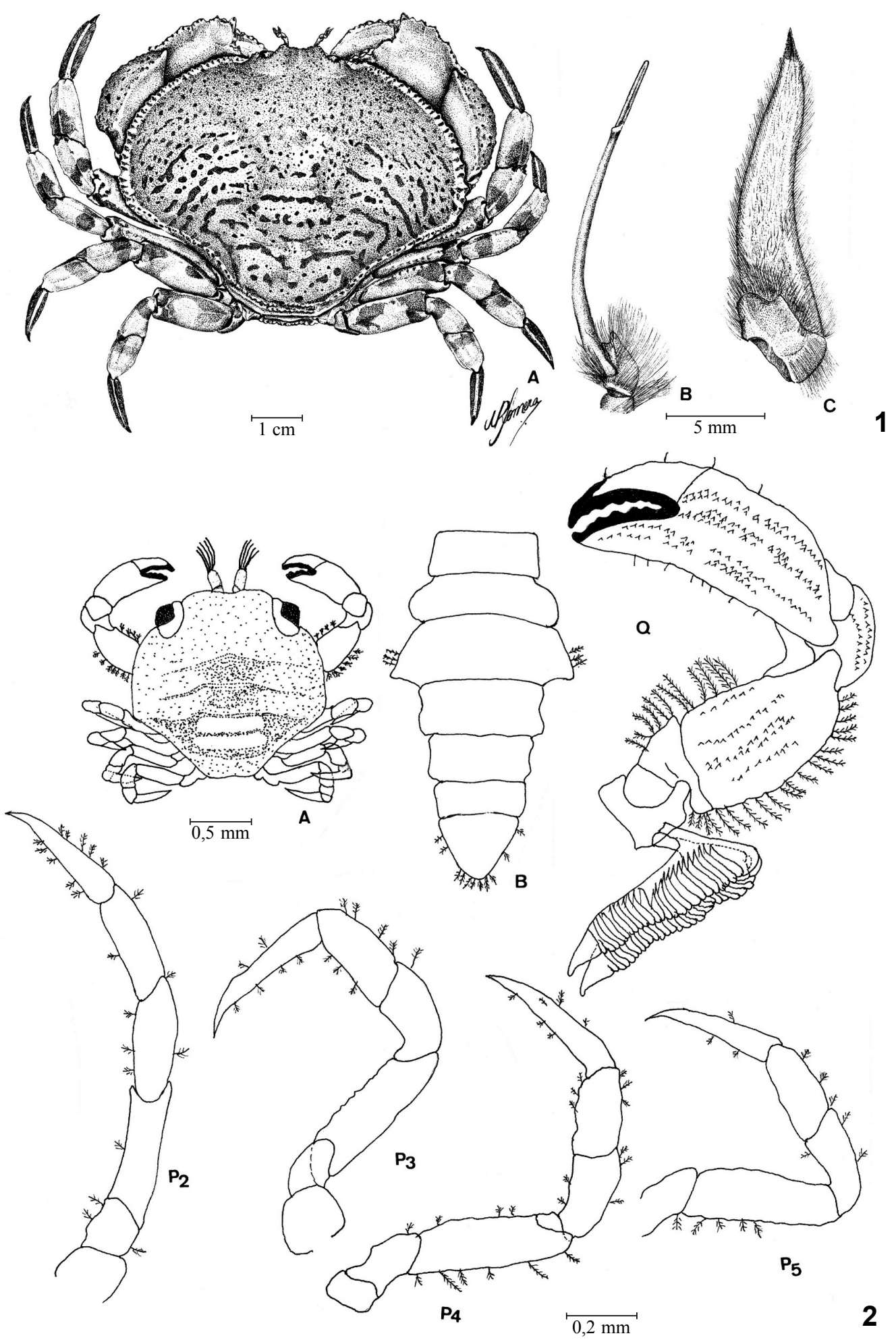

Figuras 1-2. Hepatus pudibundus. (1A) Vista dorsal de um exemplar adulto, macho; (1B) vista ventral do primeiro pleópodo esquerdo; (1C) vista ventral do segundo pleópodo; (2A) Juvenil I; (2B) abdome; $(\mathrm{Q})$ quelípodo; $\left(\mathrm{P}_{2}-\mathrm{P}_{5}\right)$ segundo ao quinto pereiópodos.

Revista Brasileira de Zoologia 20 (3): 531-539, setembro 2003 
vidas de água do mar previamente filtrada e aerada, sob as mesmas condições de temperatura e salinidade em que eclodiram.

Foram realizados três experimentos (denominados A, B e C), envolvendo um total de 240 larvas isoladas, oriundas de duas fêmeas ovígeras. Com as larvas de uma das fêmeas montou-se o experimento A, com 100 exemplares e o experimento $\mathrm{C}$, com 40 . Com as larvas da outra fêmea, montou-se o experimento B, com 100 exemplares. Os experimentos A e B destinaram-se aos estudos do desenvolvimento larval propriamente dito, publicado por Rieger \& Hebling (1993). O experimento C foi conduzido exclusivamente para a obtenção de um maior número de jovens, que somados aos dos experimentos $\mathrm{A}$ e $\mathrm{B}$, garantiriam um maior número de exemplares para os estudos da fase juvenil, objeto deste trabalho.

Os jovens também foram mantidos isolados nas mesmas condições de temperatura e salinidade em que foram criados durante o desenvolvimento larval e, a partir do terceiro estágio juvenil, transferidos para microaquários com capacidade de $100 \mathrm{ml}$, com aproximadamente $70 \mathrm{ml}$ de água do mar. O alimento para os jovens consistiu de náuplius recém-eclodidos de Artemia sp, oferecidos diariamente após a troca de água dos aquários, além de fragmentos de músculos de peixe, em intervalos de três ou quatro dias.

Os animais que morreram durante o desenvolvimento, bem como as exúvias de cada estágio juvenil, foram fixados e conservados em uma mistura de álcool etílico 96\% e glicerina, na proporção 1:1.

Os desenhos, medidas e descrições morfológicas dos estágios foram efetuados sob microscópio óptico comum e um esteromicroscópio, equipados com câmara clara e ocular micrométrica, a partir de exúvias e animais conservados. Para cada estágio do desenvolvimento juvenil, tais estudos foram realizados em 10 indivíduos.

A medida do comprimento da carapaça dos jovens foi obtida na linha mediana do corpo, entre o início da região frontal e a margem posterior da carapaça; a largura da carapaça foi obtida na altura do ângulo entre as margens ântero-lateral e póstero-lateral, que corresponde à sua maior dimensão.

A metodologia e terminologia adotadas correspondem, em linhas gerais, às utilizadas por Hebling et al. (1982), Fransozo \& Negreiros-Fransozo (1987) e Fransozo et al. (1988).

$\mathrm{Na}$ apresentação dos resultados referentes à duração e sobrevivência dos estágios, os dados são sempre cumulativos, a partir da eclosão das larvas.

\section{RESULTADOS}

\section{Desenvolvimento juvenil}

Com os experimentos de larvicultura foram obtidos 54 juvenis, sendo 38 oriundos dos cultivos A, B e 16 do cultivo C. O desenvolvimento juvenil foi acompanhado até a ecdise do oitavo para o nono estágio, quando morreu o último exemplar. As durações e sobrevivências dos oito primeiros estágios juvenis, calculadas acumulativamente a partir do dia da eclosão larval, são apresentadas na tabela I.

\section{Primeiro estágio juvenil (Figs 2-4).}

A carapaça (Fig. 2A) apresenta a região anterior côncava, desprovida da projeção frontal típica dos adultos. Sua largura
Tabela I. Hepatus pudibundus. Duração e sobrevivência dos oito primeiros estágios juvenis a partir da eclosão. (X) Duração média acumulada, em dias, ( $D$ e $D^{\prime}$ ) duração mínima e máxima, (n) número de indivíduos vivos, $(\dagger)$ número de indivíduos mortos, (S\%) porcentagem de sobrevivência. Cultivos $A$ e $B$ com $n=100$, cultivo C com $\mathrm{n}=40$.

\begin{tabular}{|c|c|c|c|c|c|c|c|c|}
\hline \multirow{2}{*}{$\frac{\text { Cultivos }}{\text { Cultivo A }}$} & \multicolumn{8}{|c|}{ Estágios } \\
\hline & $J-1$ & J-II & J-III & J-IV & $J-V$ & $J-\mathrm{VI}$ & J-VII & J-VIII \\
\hline$x$ & 46,9 & 58,7 & 77,2 & 108,2 & 146,3 & 210,6 & 258,5 & 369 \\
\hline D & 39 & 51 & 65 & 71 & 109 & 153 & 193 & 245 \\
\hline $\mathrm{D}^{\prime}$ & 59 & 76 & 138 & 165 & 221 & 397 & 422 & 507 \\
\hline $\mathrm{N}$ & 21 & 19 & 18 & 18 & 18 & 18 & 13 & 3 \\
\hline$\dagger$ & 7 & 2 & 1 & 0 & 0 & 0 & 5 & 10 \\
\hline S\% & 21 & 19 & 18 & 18 & 18 & 18 & 13 & 3 \\
\hline \multicolumn{9}{|l|}{ Cultivo B } \\
\hline$x$ & 53,7 & 66,6 & 87,3 & 112 & 139,6 & 159,4 & 202,6 & 238 \\
\hline D & 40 & 53 & 68 & 81 & 104 & 122 & 159 & 238 \\
\hline$D^{\prime}$ & 65 & 80 & 124 & 152 & 210 & 208 & 280 & 238 \\
\hline $\mathrm{N}$ & 7 & 7 & 7 & 7 & 6 & 5 & 3 & 1 \\
\hline$\dagger$ & 3 & 0 & 0 & 0 & 1 & 1 & 2 & 2 \\
\hline S\% & 7 & 7 & 7 & 7 & 6 & 5 & 3 & 1 \\
\hline \multicolumn{9}{|l|}{ Cultivo $\mathrm{C}$} \\
\hline$x$ & 44,1 & 55,2 & 69,7 & 94,8 & 133,9 & 173,4 & 256,8 & - \\
\hline D & 39 & 48 & 60 & 82 & 115 & 149 & 205 & - \\
\hline $\mathrm{D}^{\prime}$ & 60 & 71 & 84 & 124 & 150 & 202 & 294 & - \\
\hline$N$ & 14 & 13 & 13 & 13 & 12 & 12 & 10 & 0 \\
\hline$\dagger$ & 2 & 1 & 0 & 0 & 1 & 0 & 2 & 10 \\
\hline S\% & 35 & 32,5 & 32,5 & 32,5 & 30 & 30 & 25 & 0 \\
\hline
\end{tabular}

máxima é equivalente ou ligeiramente maior que o comprimento. A região dorsal é convexa, com início da diferenciação das regiões gástrica, cardíaca, intestinal e branquial. As margens são constituídas por minúsculos dentes, com distribuição bastante uniforme. Os olhos são pedunculados, bem desenvolvidos. Os quelípodos são semelhantes. As brânquias, embora não completamente formadas, atingem o mesmo número observado nos adultos, ou seja: um par de pleurobrânquias no segmento correspondente ao terceiro pereiópodo, um par de pleurobrânquias no segmento correspondente ao segundo pereiópodo, dois pares de artrobrânquias nos primeiros pereiópodos, dois pares de artrobrânquias e um par de podobrânquias nos terceiros maxilípodos, um par de artrobrânquias e um par de podobrânquias nos segundos maxilípodos. Os somitos abdominais (Fig. 2B) são individualizados, em número de seis, mais largos que longos, com o terceiro nitidamente maior que os demais. Todos eles são desprovidos de espinhos mas apresentam pequenas cerdas simples, esparsas. O telso é triangular.

Antênula (Fig. 3A): segmento basal bem desenvolvido, com 11 cerdas plumosas. Pedúnculo bisegmentado, com duas cerdas simples no segmento distal. Endopodito (flagelo ven- 

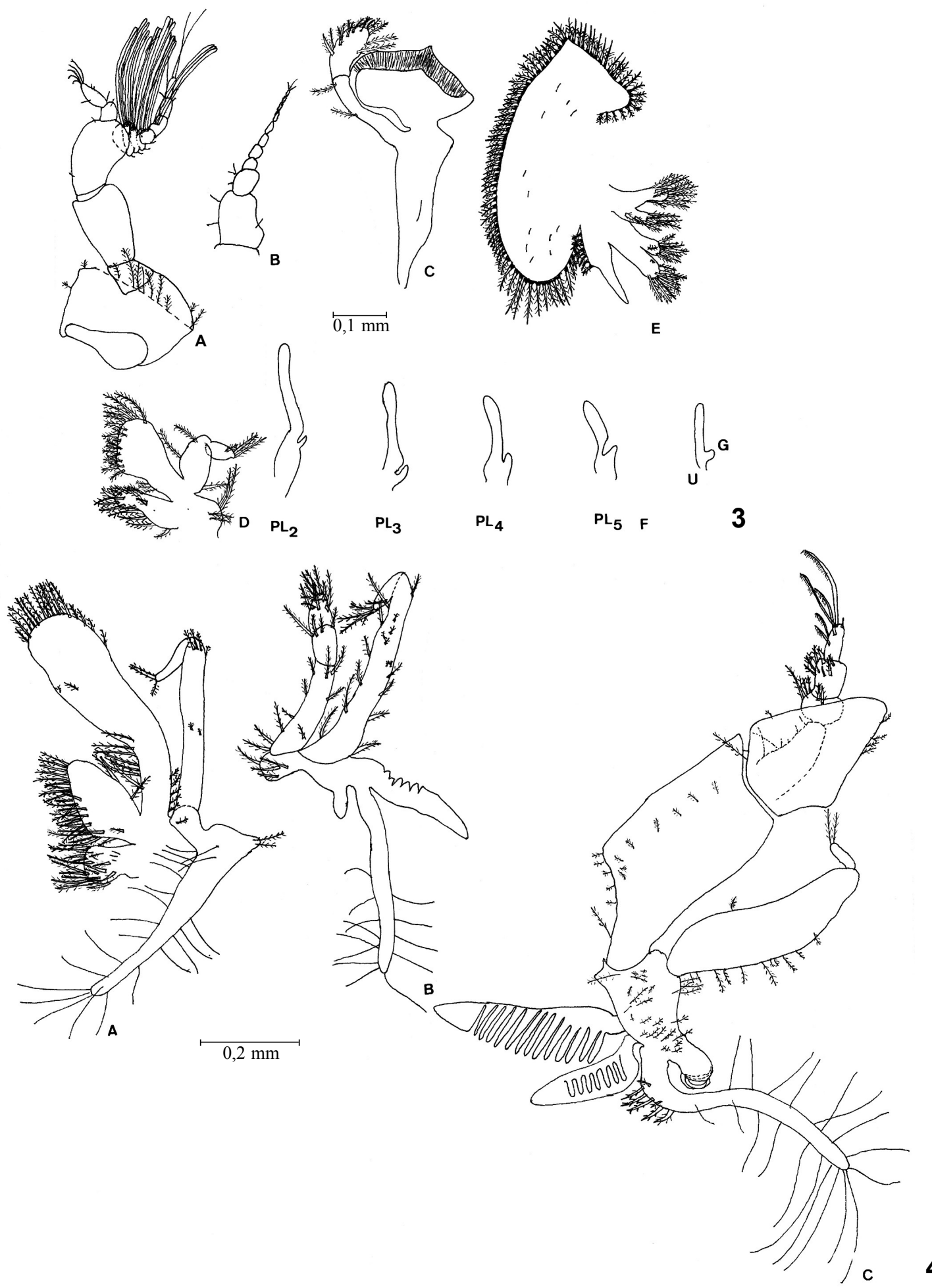

Figuras 3-4. Hepatus pudibundus, juvenil I. (3A) Antênula; (3B) antena; (3C) mandíbula; (3D) maxílula; (3E) maxila; (3F) pleópodos; (3G) urópodos; (4A) primeiro maxilípodo; (4B) segundo maxilípodo; (4C) terceiro maxilípodo.

Revista Brasileira de Zoologia 20 (3): 531-539, setembro 2003 


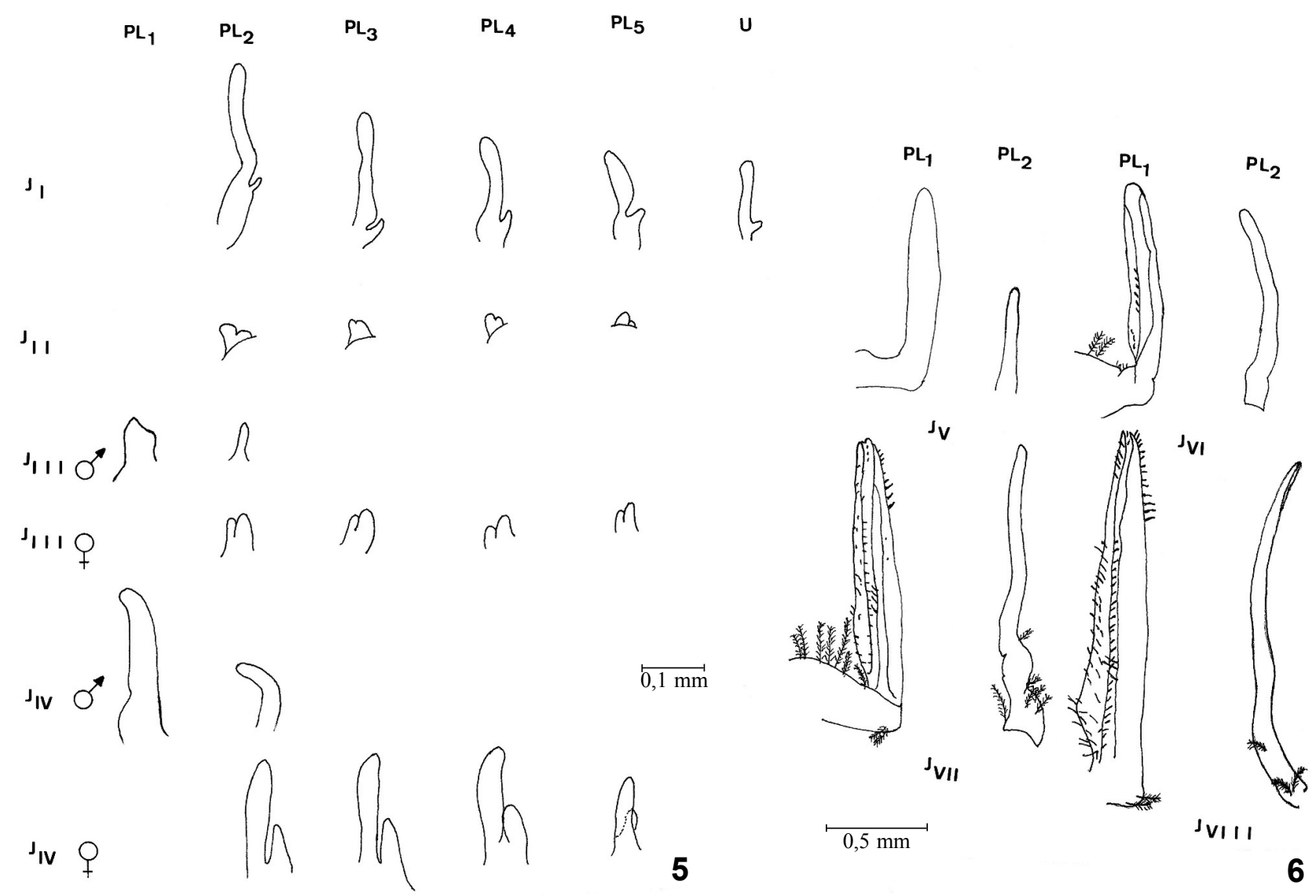

Figuras 5-6. (5) Hepatus pudibundus, pleópodos $\left(\mathrm{Pl}_{1}\right.$ a $\left.\mathrm{Pl}_{5}\right)$ e urópodos (U) do primeiro ao quarto estágios juvenis; (6) Hepatus pudibundus, pleópodos do macho $\left(\mathrm{Pl}_{1}\right.$ e $\left.\mathrm{PI}_{2}\right)$ do quinto ao oitavo estágios juvenis.

tral) bisegmentado, com uma cerda simples no segmento proximal e nove no distal. O exopodito (flagelo dorsal) é constituído por oito segmentos. O primeiro segmento é liso; o segundo, terceiro, quarto, quinto e sexto são providos de, respectivamente, 8, 8, 6, 6 e 3 estetos; o sétimo apresenta quatro cerdas simples e o oitavo, duas longas cerdas simples.

Antena (Fig. 3B): pedúnculo antenal com três cerdas simples no segmento basal, três no segundo segmento e ausência de cerdas no terceiro. O flagelo antenal é composto por sete (oito) segmentos.

Mandíbula (Fig. 3C): provida de uma lâmina cortante e um palpo bisegmentado, com duas cerdas plumosas no segmento proximal e 14 cerdas plumosas no distal.

Maxílula (Fig. 3D): endopodito não segmentado com seis cerdas plumosas. Endito basal com cerca de 23 a 25 cerdas plumosas. Endito coxal com cerca de 15 a 17 cerdas plumosas. Protopodito com quatro cerdas plumosas.

Maxila (Fig. 3E): exopodito com 73 a 93 cerdas plumosas marginais. Endopodito com oito a 10 cerdas plumosas basais. Endito basal com sete a 10 cerdas plumosas no lobo distal e oito ou nove no proximal. Endito coxal com seis a oito cerdas plumosas no lobo distal e 10 a 12 no proximal.

Primeiro maxilípodo (Fig. 4A): endopodito não segmen- tado com 15 ou 16 cerdas plumosas terminais, duas cerdas plumosas subterminais e 12 cerdas plumosas basais. Endito basal com 32 a 35 cerdas plumosas. Endito coxal com 20 a 22 cerdas plumosas. Epipodito bem desenvolvido, com duas cerdas plumosas proximais e cerdas simples medianas e distais em número de 22 . Exopodito com nove a 12 cerdas plumosas.

Segundo maxilípodo (Fig. 4B): endopodito tetrasegmentado, com cerca de 10, 4, 6, 4 cerdas plumosas, do segmento proximal para o distal. Epipodito afilado com 13 cerdas simples. Região basal do protopodito com quatro cerdas plumosas. Exopodito com três a seis cerdas plumosas terminais, uma subterminal e cerca de 17 cerdas plumosas dispostas longitudinalmente. Podobrânquia com início de formação de lamelas. Artrobrânquia rudimentar, limitada a um pequeno bulbo.

Terceiro Maxilípodo (Fig.4C): endopodito pentasegmentado, com cerca de 14, 13, 6, 8 a 13, 6 a 9 cerdas plumosas, do segmento proximal para o distal. Epipodito com 19 cerdas simples e sete cerdas plumosas basais. Protopodito com cerca de 26 cerdas plumosas. Exopodito bisegmentado com 12 cerdas plumosas no segmento proximal e nenhuma a três no distal. Artrobrânquias bem diferenciadas, lamelares. Podobrânquia com início de formação de lamelas.

Pereiópodos (Fig. 2): quelípodos (Q) simétricos, com to-

Revista Brasileira de Zoologia 20 (3): 531-539, setembro 2003 


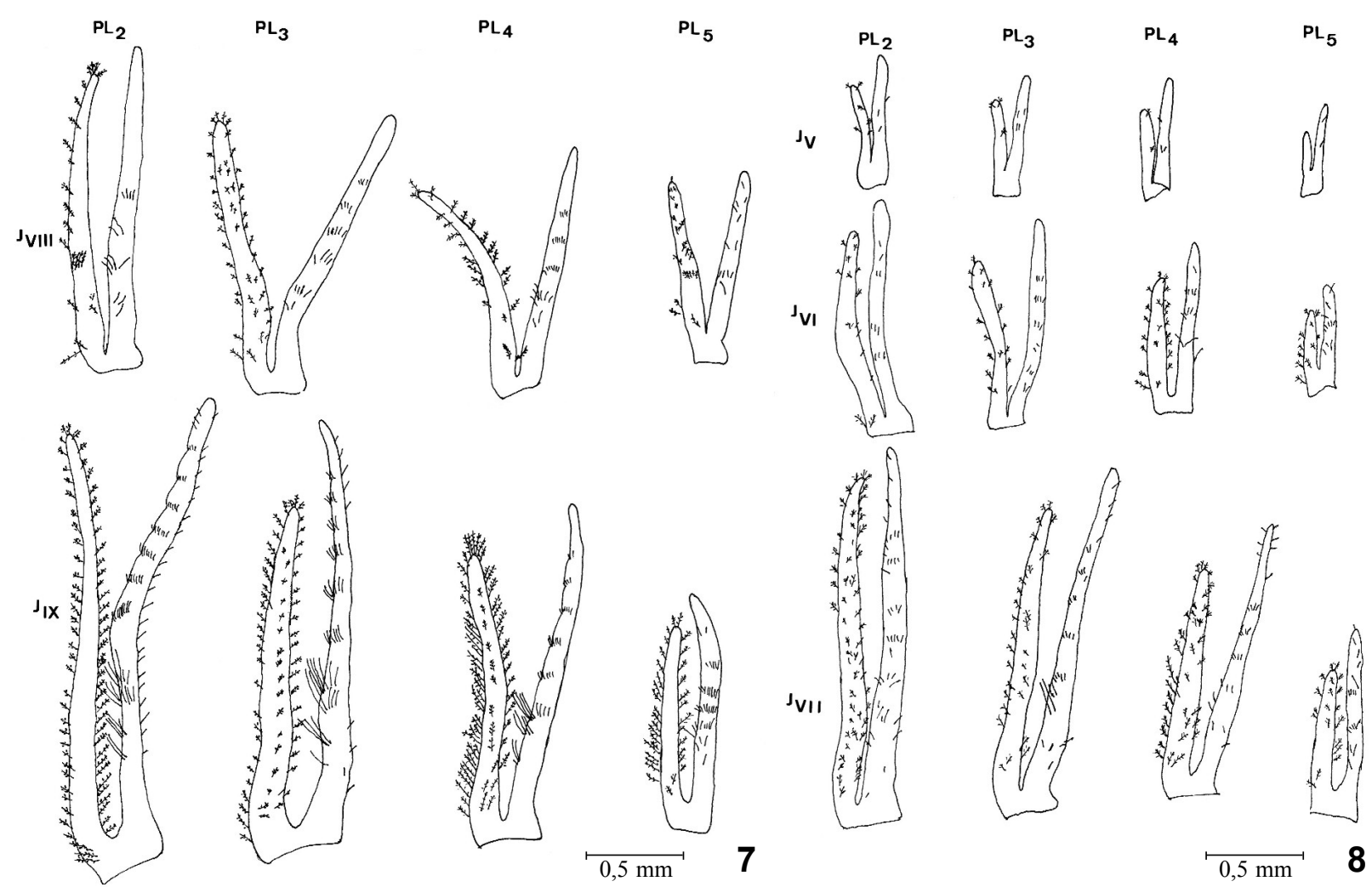

Figuras 7-8. Hepatus pudibundus, pleópodos da fêmea $\left(\mathrm{PI}_{2}\right.$ a $\left.\mathrm{PI}_{5}\right)$. (7) Do quinto ao sétimo estágios juvenis; (8) do oitavo e nono estágios juvenis.

dos os segmentos providos de pequenas cerdas simples e plumosas esparsas. O dedo fixo é provido de cinco dentes na margem interna e o dedo móvel de quatro. Artrobrânquias lamelares, mais desenvolvidas que na megalopa. Segundo, terceiro, quarto e quinto pereiópodos $\left(\mathrm{P}_{2}\right.$ a $\mathrm{P}_{5}$ bastante semelhantes, com numerosas cerdas simples ou plumosas, esparsas. O quinto pereiópodo não apresenta mais as três longas cerdas unciformes no dáctilo, típicas do estágio anterior (megalopa).

Pleópodos (Fig. 3F): rudimentares, desprovidos de cerdas, em número de quatro pares $\left(\mathrm{Pl}, \mathrm{a} \mathrm{Pl}_{5}\right)$, localizados ventralmente, do segundo ao quinto somitos abdominais.

Urópodos (Fig. 3G): um par, menor que os pleópodos, desprovidos de cerdas.

\section{Segundo ao oitavo estágio juvenil.}

A partir do segundo estágio juvenil constatou-se que os animais, apesar de aparentemente semelhantes no aspecto geral, começam a sofrer importantes modificações morfológicas, sobretudo na diferenciação dos caracteres sexuais secundários. A carapaça, que no primeiro estágio juvenil era aproximadamente quadrangular, torna-se, como nos adultos, mais larga que longa, em todos os estágios subsequentes, cujas medidas são apresentadas na tabela II.

Com relação aos apêndices, as principais modificações morfológicas encontradas nos oito primeiros estágios do desenvolvimento juvenil são indicadas na tabela III.
Tabela II. Hepatus pudibundus. Medidas ( $\mathrm{mm}$ ) do comprimento da carapaça (C) e largura da carapaça (L), do I ao VIII estágio juvenis. (X) Média, (S) desvio padrão, (I.C.) intervalo de confiança, (L/C) razão entre a largura e o comprimento, $\mathrm{n}=20$.

\begin{tabular}{lcrrrrrr}
\hline Estágio & & X & Max. & Mín. & S & I.C. & L/C \\
\hline J-I & L & 1,66 & 1,78 & 1,54 & 0,007 & $1,66 \pm 0,003$ & \\
& C & 1,56 & 1,76 & 1,44 & 0,009 & $1,56 \pm 0,004$ & 1,06 \\
J-II & L & 2,50 & 2,63 & 2,26 & 0,012 & $2,50 \pm 0,005$ & \\
& C & 2,09 & 2,23 & 1,89 & 0,010 & $2,09 \pm 0,004$ & 1,19 \\
J-III & L & 3,37 & 3,70 & 2,45 & 0,027 & $3,37 \pm 0,012$ & \\
& C & 2,66 & 2,95 & 2,10 & 0,019 & $2,66 \pm 0,008$ & 1,26 \\
& L & 4,41 & 5,39 & 3,28 & 0,040 & $4,41 \pm 0,018$ & \\
J-IV & C & 3,47 & 4,15 & 2,66 & 0,031 & $3,47 \pm 0,014$ & 1,27 \\
& L & 5,42 & 6,85 & 4,08 & 0,071 & $5,42 \pm 0,033$ & \\
J-V & C & 4,26 & 5,39 & 3,31 & 0,054 & $4,26 \pm 0,025$ & 1,27 \\
& L & 7,11 & 8,64 & 5,52 & 0,072 & $7,11 \pm 0,033$ & \\
J-VI & C & 5,65 & 6,96 & 4,32 & 0,060 & $5,65 \pm 0,028$ & 1,25 \\
& L & 8,96 & 10,2 & 7,08 & 0,087 & $8,96 \pm 0,040$ & \\
J-VII & C & 7,02 & 7,92 & 5,76 & 0,068 & $7,02 \pm 0,031$ & 1,27 \\
& L & 10,96 & 12,0 & 8,88 & 0,078 & $10,96 \pm 0,036$ & \\
J-VIII & C & 8,53 & 9,72 & 6,84 & 0,060 & $8,53 \pm 0,028$ & 1,28 \\
& C & & & & & &
\end{tabular}


Tabela III. Hepatus pudibundus. Caracteres morfológicos que permitem a identificação dos oito primeiros estágios juvenis, $\mathrm{n}=10$.

\begin{tabular}{|c|c|c|c|c|c|c|c|c|}
\hline Caracteres morfológicos & $\mathrm{H}-\mathrm{I}$ & $\mathrm{J}-\mathrm{II}$ & J-III & $\mathrm{J}-\mathrm{IV}$ & $\mathrm{J}-\mathrm{V}$ & $\mathrm{J}-\mathrm{VI}$ & $\mathrm{J}-\mathrm{VII}$ & J-VIII \\
\hline Segmentos do exopodito da antênula & $7-8$ & $7-8$ & $8-9$ & $9-11$ & $10-12$ & $11-14$ & $12-14$ & $13-17$ \\
\hline Segmentos do endopodito da antênula & 2 & 2 & $2-3$ & 3 & 3 & $3-4$ & $3-4$ & 4 \\
\hline Segmentos da antena & $7-8$ & 5 & 5 & 5 & 5 & 5 & 5 & 5 \\
\hline Cerdas do segmento basal do endopodito da maxilula & 2 & $3-4$ & 5 & $7-11$ & $10-12$ & $11-18$ & $14-22$ & $18-35$ \\
\hline Cerdas do endito basal da maxilula & $23-25$ & $24-29$ & $31-38$ & $41-59$ & $46-63$ & $60-72$ & $69-93$ & 73-118 \\
\hline Cerdas do endito coxal da maxilula & $15-17$ & $12-17$ & $16-21$ & $20-24$ & $24-30$ & $28-39$ & $31-46$ & $33-55$ \\
\hline Cerdas marginais do exopodito da maxila & $73-93$ & $97-116$ & $132-160$ & $184-223$ & $229-248$ & $253-301$ & $364-389$ & $396-496$ \\
\hline Cerdas basais do endopodito da maxila & $8-10$ & $10-12$ & $14-17$ & $18-25$ & $26-30$ & $32-40$ & $45-68$ & $50-88$ \\
\hline Cerdas do lobo distal do endito basal da maxila & $7-10$ & $8-12$ & $12-19$ & $18-28$ & $24-31$ & $26-45$ & $39-56$ & $52-81$ \\
\hline Cerdas do lobo proximal do endito basal da maxila & $8-9$ & $9-10$ & $11-12$ & $2-18$ & $15-20$ & $18-27$ & $26-41$ & 29-62 \\
\hline Cerdas do lobo distal do endito coxal da maxila & $6-8$ & $6-8$ & $8-10$ & $7-10$ & $8-2$ & $10-14$ & $11-16$ & $12-18$ \\
\hline Cerdas do lobo proximal do endito coxal da maxila & $10-12$ & $12-15$ & $15-18$ & $16-23$ & $20-25$ & $24-30$ & $24-37$ & $31-51$ \\
\hline Cerdas apicais do endopodito do $1^{\circ}$ maxílipodo & $15-16$ & $16-20$ & $21-23$ & $25-30$ & $28-35$ & $33-37$ & $37-54$ & $37-58$ \\
\hline Cerdas apicais do exopodito do $1^{\circ}$ maxílipodo & 3-5 & $5-7$ & $5-9$ & $10-13$ & $13-15$ & $14-20$ & $18-24$ & $19-33$ \\
\hline Cerdas do endito basal do $1^{\circ}$ maxílipodo & $32-35$ & $53-62$ & $67-83$ & $94-148$ & 137-166 & $153-203$ & 194-301 & $266-395$ \\
\hline Cerdas do endito coxal do $1^{\circ}$ maxilipodo & $20-22$ & $21-34$ & $35-44$ & $55-89$ & $96-110$ & $120-154$ & $140-184$ & $190-373$ \\
\hline Cerdas do penúltimo segmento do endopodito do $2^{\circ}$ maxílipodo & $7-8$ & $7-10$ & $10-13$ & $12-21$ & $19-21$ & $18-29$ & $24-36$ & $32-48$ \\
\hline Cerdas do último segmento do endopodito do $2^{\circ}$ maxílipodo & $9-10$ & $9-13$ & $11-14$ & $14-18$ & $15-18$ & $16-24$ & $23-30$ & $25-35$ \\
\hline Cerdas do último segmento do exopodito do $2^{\circ}$ maxílipodo & $4-6$ & $5-8$ & $9-10$ & $12-14$ & $16-19$ & $16-22$ & $20-30$ & $24-36$ \\
\hline Cerdas do penúltimo segmento do endopodito do $3^{\circ}$ maxílipodo & $8-13$ & $14-17$ & $16-25$ & $32-55$ & $46-59$ & $55-92$ & $90-145$ & $145-367$ \\
\hline Cerdas do último segmento do endopodito do $3^{\circ}$ maxílipodo & $6-9$ & $7-9$ & $9-12$ & $11-18$ & $15-18$ & $18-28$ & $20-36$ & $30-48$ \\
\hline Cerdas do último segmento do exopodito do $3^{\circ}$ maxilipodo & $0-3$ & $0-2$ & $0-3$ & $0-4$ & $2-5$ & $3-7$ & 3-9 & 3-11 \\
\hline Comprimento do ísquio do endopodito da $3^{\circ}$ maxílipodo $(\mathrm{mm})$ & $0,46-0,60$ & $0,56-0,74$ & $0,84-0,94$ & $1,06-1,38$ & $1,30-1,58$ & $1,50-2,12$ & $1,92-2,99$ & $2,55-3,60$ \\
\hline
\end{tabular}

No que diz respeito à diferenciação dos caracteres sexuais secundários, verificou-se que as modificações mais acentuadas ocorrem nos pleópodos, cuja evolução morfológica, nos jovens de ambos os sexos, é mostrada nas figuras 5 a 8 . No primeiro estágio juvenil (Fig. 5JI), os pleópodos são em número de quatro pares $\left(\mathrm{Pl}_{2}\right.$ a $\left.\mathrm{Pl}_{5}\right)$ seguidos de um par de urópodos, tal como na megalopa. Todavia, são acentuadamente menores que os da megalopa e totalmente desprovidos de cerdas. No segundo estágio juvenil (Fig. 5JII), os pleópodos, tornam-se rudimentares, enquanto que os urópodos (U) desaparecem. No terceiro estágio juvenil (Fig. 5JIII), se o animal for macho, surgem os rudimentos de um novo par de pleópodos $\left(\mathrm{Pl}_{1}\right)$, no primeiro somito abdominal, concomitantemente com uma diferenciação do segundo par $\left(\mathrm{Pl}_{2}\right)$ e o desaparecimento dos demais $\left(\mathrm{Pl}_{3}, \mathrm{Pl}_{4}, \mathrm{Pl}_{5}\right)$. Se o animal for do sexo feminino, os pleópodos continuam em número de 4 pares $\left(\mathrm{Pl}_{2}\right.$ a $\left.\mathrm{Pl}_{5}\right)$ mas crescem e adquirem a forma birreme. A partir do quarto estágio juvenil (Fig. 5JIV), os pleópodos irão apenas crescer e sofrer as alterações morfológicas inerentes a cada sexo (Figs 6-8), sem nenhuma variação numérica adicional, até a fase adulta.

A morfologia geral das brânquias também é completada no quarto estágio juvenil, com a diferenciação lamelar da artrobrânquia correspondente ao segundo maxilípodo.

Os orifícios sexuais só se definem, como aberturas propriamente ditas, a partir do quinto estágio juvenil. Os orifícios sexuais masculinos localizam-se nas coxas do quinto par de pereiópodos enquanto que os femininos alojam-se no sexto esternito torácico.

\section{DISCUSSÃO}

Em função do total desconhecimento sobre as formas juvenis das espécies classicamente incluídas na família Calappidae, torna-se praticamente impossível qualquer tentativa visando a definição de caracteres que lhes sejam peculiares, nesta fase da vida. Nestas condições, as análises comparativas dos caracteres juvenis de $H$. pudibundus só poderão ser efetuadas com umas poucas espécies pertencentes a outras famílias de Brachyura e, mesmo assim, à um nível mais geral, como a diferenciação das brânquias e dos caracteres sexuais secundários. Com relação às brânquias, $H$. pudibundus as apresentam numericamente completas (nove pares) no primeiro estágio juvenil, embora a artrobrânquia correspondente ao segundo maxilípodo ainda seja limitada a um pequeno bulbo. A partir do quarto estágio juvenil esta artrobrânquia também adquire a forma lamelar, com morfologia geral semelhante à dos adultos. Em Pilumnus novaezealandiae Filhol, 1886 e P. lumpinus Bennett, 1964 (Xanthidae), que apresentam desenvolvimento direto, de acordo com WEAR (1967), as brânquias já estão numericamente completas no final da fase de zoea, antes da eclosão, que 
ocorre como megalopa. Em P. novaezealandiae a complementação da morfologia branquial também é abreviada, com lamelas bem desenvolvidas a partir do segundo estágio juvenil. Parthenope serrata (H. Milne Edwards, 1834) (Parthenopidae), estudada por YANG (1971), apresenta brânquias numericamente completas no segundo estágio juvenil, tal como ocorre no Grapsidae Cyrtograpsus angulatus Dana, 1851, segundo Rieger \& BELTRÃo (2000). A complementação da morfologia branquial, nestas espécies, não foi mencionada pelos referidos autores. Em Libinia erinacea (A. Milne Edwards, 1879) (Majidae), YANG \& McLaUghlin (1979), encontraram nove pares de brânquias no segundo estágio juvenil, mas a morfologia específica só foi observada no sexto estágio juvenil. Em outros Majidae estudados por HoNG (1988), constatou-se que o número de brânquias varia de sete a nove pares, em função da ausência da podobrânquia e/ou artrobrânquia do segundo maxilípodo que, quando presentes, só se desenvolvem após a fase de megalopa. O Portunidae Carcinus maenas (Linnaeus, 1758), segundo este mesmo autor, também apresenta nove pares de brânquias no segundo estágio juvenil mas a complementação morfológica ocorre no quinto estágio. Fato singular, também constatado por HoNG (1988), ocorre na ontogenia de algumas espécies de Pinnotheridae, quando as larvas sofrem uma redução de tamanho da artrobrânquia anterior do terceiro maxilípodo ou sua fusão com a artrobrânquia posterior, além da degeneração da podobrânquia deste apêndice. Com resultado, ficam com apenas um par de artrobrânquias no terceiro maxilípodo que, juntamente com os outros dois correspondentes ao primeiro pereiópodo, totalizam os três únicos pares de brânquias que ocorrem nos adultos.

Considerando-se o conceito geral de que a evolução dos Decapoda foi acompanhada por uma redução no número de brânquias (BURKENROAD 1981, HONG 1988), pode-se inferir que os estudos sobre ontogenia branquial deverão elucidar mais alguns aspectos da filogenia e, consequentemente, da ainda discutível classificação deste grupo de animais.

No que diz respeito à diferenciação dos caracteres sexuais secundários, as maiores modificações ocorrem nos pleópodos que, em $H$. pudibundus, manifestam-se a partir do terceiro estágio juvenil, com a presença de dois pares $\left(\mathrm{Pl}_{1}\right.$ e $\left.\mathrm{Pl}_{2}\right)$, no macho e quatro pares $\left(\mathrm{Pl}_{2}, \mathrm{PL}_{3}, \mathrm{Pl}_{4}, \mathrm{Pl}_{5}\right)$, na fêmea. Embora tenha sido estudado em um pequeno número de espécies, pode se inferir que o início da diferenciação pleopodial, em Brachyura, não apresenta uniformidade, podendo ocorrer em diferentes estágios da fase juvenil, independentemente do grupo taxonômico considerado. Assim, entre os Grapsidae, esta diferenciação sexual já pode ser observada no primeiro estágio juvenil, conforme relatado por HaRTNOLL (1992) em Percnon abbreviatum (Dana, 1851). Nesta mesma família, Flores et al. (1998) constataram que em Pachygrapsus transversus (Gibbes, 1850) ocorre no segundo estágio; Rieger \& NAKAgaWA (1995) verificaram que em Chasmagnathus granulata Dana, 1851 é no terceiro estágio; em Cyrtograpsus angulatus Dana, 1851, no quarto estágio (RiEgER \& Beltrão 2000); em Sesarma rectum Randall, 1840 no $12^{\circ}$ estágio (Fransozo 1987).

Na família Xanthidae, o início da diferenciação pleopodial ocorre no terceiro estágio juvenil em Pilumnus vestitus Haswell, 1882, estudado por Hale (1931) ou no quarto estágio juvenil, conforme constatado em outras espécies por WEAR (1967), Hebling et al. (1982), Fransozo \& Negreiros-Fransozo (1987) e Fransozo et al. (1988). Dentre os Portunidae, Carcinus maenas (Linnaeus, 1758) apresenta diferenciação pleopodial no $2^{\circ}$ estágio juvenil (SHEN 1935) e Callinectes sapidus Rathbun, 1896, no quarto estágio (BARUTOT et al. 2001). No Majidae Inachus dorsetensis (Pennant, 1777) ocorre no terceiro estágio (INGLE 1977).

Dentre os Grapsidae, melhor estudados sob este aspecto, FloRes et. al (1998) inferiram que nas espécies das subfamílias Grapsinae e Plagusiinae as megalopas são maiores e o desenvolvimento juvenil é mais rápido, com maturidade sexual precoce. Os Sesarminae, ao contrário, apresentam megalopas menores, passam por uma maior sequência de estágios juvenis, com maturidade mais demorada.

Felder et. al. (1985) já haviam demonstrado a importância do conhecimento sobre os primeiros estágios pós-larvais na avaliação do tamanho do corpo, morfologia, freqüência de mudas, taxa de crescimento, alimentação, comportamento, habitat e até mesmo na obtenção de indicações sobre a filogenia de alguns grupos de Decapoda, quando associados com as informações sobre as larvas e adultos.

Os estudos sobre crescimento relativo em H. pudibundus, efetuados por Mantelatto \& Fransozo (1994), indicaram que a maturidade sexual é alcançada quando os animais atingem 34$36 \mathrm{~mm}$ de largura da carapaça. Posteriormente, Reigada \& NEGreiros-Fransozo (1999) determinaram que, em ambos os sexos, $H$. pudibundus alcança a maturidade morfológica e gonadal com 32-34 mm de largura da carapaça.

Considerando as medidas da largura da carapaça dos oito primeiros estágios juvenis obtidos no presente estudo, associadas com o incremento de tamanho entre as ecdises sucessivas, pode-se inferir que $H$. pudibundus deve atingir a maturidade sexual ao redor do $13^{\circ}$ estágio, quando alcança os valores determinados pelos autores acima citados. Da mesma forma, levando-se em conta que os cultivos em laboratório sempre acarretam um maior tempo de desenvolvimento, é possível prever que, na natureza, a maturidade sexual deve ser obtida quando os animais completam o primeiro ano de vida.

\section{AGRADECIMENTOS}

Expressamos nossos agradecimentos ao Sr. Jaime Roberto Somera, desenhista do Departamento de Zoologia, Instituto de Biociências, Campus de Rio Claro, UNESP, pela cuidadosa e paciente elaboração da figura 1. O segundo autor agradece também a esta instituição pela acolhida e facilidades oferecidas durante a realização do Curso de Pós-graduação e especialmente ao Prof. Dr. Nilton José Hebling, pela orientação proporcionada.

\section{REFERÊNCIAS BIBLIOGRAFICAS}

Barutot, R.A.; R.R.R. Vieira \& P.J. Rieger. 2001. Desenvolvimento juvenil de Callinectes sapidus Rathbun, 1896 (Crustacea: Decapoda: Portunidae), em laboratório, a partir de megalopas coletadas no plancton. Comunicações do $\mathbf{M u -}$ seu de Ciências e Tecnologia PUCRS, Série Zoologia, Porto Alegre, 14 (1): 23-42.

BurkENROAD, M.D. 1981. The higher taxonomy and evolution of Decapoda (Crustacea). Transactions of the San Diego Society of Natural History, San Diego, 19 (17): 251-268.

Felder, D.L.; J.W. Martin \& J.W. Goy. 1985. Patterns in early postlarval development of decapods, p. 163-225. In: A.M. 
WenNer (Ed.). Larval Growth. Santa Barbara, University of California, 248p.

Flores, A.A.V.; M.L. Negreiros-Fransozo \& A. Fransozo. 1998. The megalopa and juvenile development of Pachygrapsus transversus (Gibbes, 1850) (Decapoda, Brachyura), compared with other grapsids crabs. Crustaceana, International Journal of Crustacean Research, Leiden, 71 (2): 197-222.

Fransozo, A. 1987. Desenvolvimento dos estágios juvenis de Sesarma (Holometopus) rectum randall, 1840 (Decapoda, Grapsidae) obtidos em laboratório. Naturália, São Paulo, 11/12: 77-87.

Fransozo, A. \& M. L. Negreiros-Fransozo. 1987. Morfologia dos primeiros estágios juvenis de Eriphia gonagra (Fabricius, 1781) e Eurypanopeus abbreviatus (Stimpson, 1860) (Crustacea, Decapoda, Xanthidae) obtidos em laboratorio. Papéis Avulsos de Zoologia, São Paulo, 36 (22): 257-277.

Fransozo, A; M.L. Negreiros-Fransozo \& C.M. Hiyodo. 1988. Développement juvénile de Menippe nodifrons Stimpson, 1859 (Crustacea, Decapoda, Xanthidae) au laboratoire. Revue D' Hydrobiologie Tropicale, Paris, 21 (4): 297-308.

HaLe, H.M. 1931. The post embryonic development of Autralian xanthid crab (Pilumnus vestitus, Haswell). Records of the South Australian Museum, Adelaide, 4: 321-331

HaRTNOLL, R.G. 1992. Megalopae and early post-larval stages of East African Percnon abbreviatum (Decapoda: Brachyura: Grapsidae). Journal of Zoology, London, 228: 51-67.

Hebling, N.J.; A. Fransozo \& M.L. Negreiros-Fransozo. 1982. Desenvolvimento dos primeiros estágios juvenis de Panopeus herbstii H. Milne Edwards, 1834 (Crustacea, Decapoda, Xanthidae), criados em laboratório. Naturália, São Paulo, 7: $177-188$.

Hong, S.Y. 1988. Development of epipods and gills in some pagurids and brachyurans. Journal of Natural History, London, 22: 1005-1040.

INGLE, R.W. 1977. The larval and post-larval development of the scorpion spider crab, Inachus dorsettensis (Pennant) (family: Majidae), reared in the laboratory. Bulletin of the British Museum (Natural History): Zoology, London, 30: 329-348.

Mantelatto, F.L.M. \& A. Fransozo. 1992. Relação peso/largura da carapaça no caranguejo Hepatus pudibundus (Herbst, 1785) (Crustacea, Decapoda, Calappidae) na região de Ubatuba, SP. Brasil. Brazilian Archives of Biology and Technology, Curitiba, 35 (4): 719-724.

. 1994. Crescimento relativo e dimorfismo sexual em Hepatus pudibundus (Herbst, 1785) (Decapoda, Brachyura) no litoral norte paulista. Papéis Avulsos Zoologia, São Paulo. 39 (4): 33-48

Mantelatto, F.L.M.; A. Fransozo \& M.L. Negreiros-Fransozo. 1995b. Population structure of Hepatus pudibundus (Decapoda: Calappidae) in Fortaleza Bay, Brazil. Revista de Biologia Tropical, Costa Rica, 43 (1-3): 265-270. 1995a. Distribuição do caranguejo Hepatus pudibundus (Herbst, 1785) (Decapoda, Decapoda, Brachyura) na Enseada da Fortaleza, Ubatuba (SP), Brasil. Boletim do Instituto Oceanográfico, São Paulo, 43 (1): 51-61.

Mantelatto, F.L.M. \& M. Petracco. 1997. Natural diet of the crab Hepatus pudibundus (Brachyura: Calappidae) in Fortaleza Bay, Ubatuba (SP), Brazil. Journal of Crustacean Biology, Washington, 17 (3): 440-446.

Melo, G.A.S. 1996. Manual de identificação dos Brachyura (Caranguejos e Siris) do litoral brasileiro. São Paulo. Ed. Plêiade., $603 p$.

Reigada, A.L.D. \& M.L. Negreiros-Fransozo. 1995. Fecundidade do caranguejo Hepatus pudibundus (Herbst, 1785) (Crustacea, Decapoda, Calapidae) em Ubatuba (SP), Brasil. Brazilian Archives of Biology and Technology, Curitiba, 38 (2): 661668.

Reigada, A.L.D. \& M.L. Negreiros-Fransozo \& F.L.M. Mantellato. 1994. Avaliação do tamanho dos quelípodos de Hepatus pudibundus (Herbst, 1785) (Crustacea, Calapidae), em relação ao sexo e à maturação. Brazilian Archives of Biology and Technology, Curitiba, 37 (4): 797-807.

. 1999. Maturidade sexual em Hepatus pudibundus (Decapoda, Brachyura, Calappidae). Iheringia, Série Zoologia, Porto Alegre, (86): 159-164.

Rieger, P.J. \& R. Beltrão. 2000. Desenvolvimento juvenil de Cyrtograpsus angulatus Dana (Crustacea, Decapoda, Grapsidae), em laboratório. Revista Brasileira de Zoologia, Curitiba, 17 (2): 405-420.

Rieger, P.J. \& N.J. Hebling. 1993. Desenvolvimento larval de Hepatus pudibundus (Herbst, 1785) (Decapoda, Calapidae), em laboratório. Revista Brasileira de Biologia, São Paulo, 53 (4): 513-528.

Rieger, P.J. \& C. Nakagawa. 1995. Desenvolvimento juvenil de Chasmagnathus granulata Dana, 1851 (Crustacea, Decapoda, Grapsidae), em laboratório. Nauplius, Rio Grande, 3: 59-74.

SHEN, C. H. 1935. An investigation of the post-larval development of the shore-crab Carcinus maenas, with special reference to the external secondary sexual characteres. Proceedings of the Zoological Society of London, London, (1): $1-33$

WeAR, R.G. 1967. Life history studies on New Zealand Brachyura. I. Embryonic and post-embryonic development of Pilumnus novaezealandiae Filhol, 1886, and of Pilumnus lumpinus Bennet, 1964 (Xanthidae, Pilumninae). New Zealand Journal of Marine and Freshwater Research, New Zealand, 1: 482-535.

YANG, W.T. 1971. The larval and post-larval development of Parthenope serrata reared in the laboratory and the systematic position of the Parthenopidae (Crustacea, Brachyura). Biological Bulletin. Massasuchets, 140 (1): 166-189.

YANG, W.T \& P.A. Maclaughlin. 1979. Development of the epipodite of the second maxilliped and gills in Libinia erinacea (Decapoda, Brachyura, Oxyrhyncha). Crustaceana, (Suppl. 5), Leiden, 47-54.

Recebido em 21.X.2002; aceito em 28.VIII.2003. 